\title{
Performance of semi-dry anaerobic co-digestion of swine manure with rice straw under biogas slurry addition
}

\author{
Xiaoyong Qian ${ }^{1, a}$, Genxiang Shen ${ }^{1, b}$, Zhenqi Wang ${ }^{1, c}$, Jinwen $\mathrm{Li}^{1, \mathrm{~d}}$, Zhongfang \\ Lei $^{2, \text { e }}$, Zhenya Zhang ${ }^{2, f}$ \\ ${ }^{1}$ Shanghai Academy of Environmental Sciences, Shanghai 200233, China; \\ ${ }^{2}$ Graduate School of Life and Environmental Sciences, University of Tsukuba, Tsukuba, Ibaraki \\ 305-8572, Japan. \\ aqianxy@saes.sh.cn, bshengx@ saes.sh.cn, ${ }^{c}$ Wangzq@ saes.sh.cn, ${ }^{\mathrm{d}} \mathrm{Lijw} @$ saes.sh.cn, \\ Iei.zhongfang.gu@u.tsukuba.ac.jp, ${ }^{\mathrm{f}}$ zhang.zhenya.fu@u.tsukuba.ac.jp
}

\begin{abstract}
Keywords: anaerobic digestion; semi-dry condition; inoculum; swine manure; rice straw; first-order model.
\end{abstract}

\begin{abstract}
The aim of this study was to evaluate the effect of biogas slurry inoculation on semi-dry anaerobic co-digestion of swine manure and rice straw, focusing on biogas production and kinetics. Biogas slurry from digested swine manure was applied as inoculum, and the effect was evaluated in batch reactors. The results indicated that biogas slurry inoculation could increase biogas yield by $3.00-7.05 \%$, and improve biogas productivity by $7.48-8.17 \%$, for per unit of TS. The digestion process fitted the single-stage first-order model well, and the reactors inoculated with biogas slurry exhibited faster in biogas production with the biogas production rate constant $(k)$ increased by $39.90-50.96 \%$ compared to the control reactor.
\end{abstract}

\section{Introduction}

As one of the biggest agricultural countries, China produces more than 0.3 billion tons and 0.2 billion tons of animal manure and crop straw according to the statistical yearbook of China in 2010, and serious water and air pollution has been caused due to inappropriate disposal of animal manure and open burning of crop straw [1,2], in which, swine manure and rice straw are the major agricultural wastes [3]. Agricultural waste management has become one of the largest environmental concerns in the recent past in China, and anaerobic digestion has been considered the main commercially viable option for both agricultural waste treatment and energy/nutrition generation from 1980s [2, 4].

Anaerobic digestion is a biological process wherein diverse group of microorganism convert the complex organic matter into a simple and stable end products in the absence of oxygen. This process is very attractive because it yields biogas, a mixture of methane $\left(\mathrm{CH}_{4}\right)$ and carbon dioxide $\left(\mathrm{CO}_{2}\right)$, which can be used as renewable energy resources [5-8]. The anaerobic digestion process can be divided into wet $(<10 \% \mathrm{TS})$, semi-dry $(10-20 \% \mathrm{TS})$, and dry $(>20 \% \mathrm{TS})$ digestion processes depending on the total solid (TS) concentration of the feedstock [9]. There are lots of studies about wet and dry digestions in the past several decades [10], and semi-dry digestion is currently garnering attention, which is favorable in terms of less production of digester effluent requiring dewatering compared to wet digestion, and a low energy requirement mixing and pumping compared to dry digestion $[4,11,12]$.

Anaerobic digesters are mainly handled in batch mode or continuous plug-flow mode, demonstrating various limitations including large inoculation, mixing, and possibility of instability and difficulty in overcoming this instability [13-14]. Inoculation phase is an important step affecting high-solid anaerobic digestion, and inoculums should contain active microbial communities, which are needed for anaerobic digestion $[2,15]$. The digestates produced in anaerobic engineering projects have been sources for these inoculums [16-20]. Previous studies analyzed the effect of different inoculums on methane yield with different substrates, and some contradictory results were also 
obtained [21-23]. Few attempts have been tried to study the effect of biogas slurry from digested swine manure on the semi-dry anaerobic co-digestion using swine manure and rice straw as substrates.

\section{Materials and methods}

Substrate and inoculum. The swine manure (SM) was collected from a swine farm in Pudong District, Shanghai, China with a productivity of 8,000 heads per year, and the rice straw (RS) was sampled from a paddy field in Qingpu District, Shanghai, China. In the experiment, rice straw was milled to the size of $1-2 \mathrm{~cm}$, and mixed with fresh swine manure thoroughly. The inoculum was biogas slurry obtained from a biogas production project in a swine farm in Chongming County, Shanghai, China. The characteristics of substrate and inoculum were listed in Table 1.

Table 1 Characteristics of substrate and inoculum used in the experiment

\begin{tabular}{llll}
\hline Parameters & Swine manure & Rice straw & Biogas slurry \\
\hline TS (\%) & $13.41 \pm 0.54$ & $82.90 \pm 3.79$ & $1.78 \pm 0.54$ \\
TOC(\%, d.w.) & $40.35 \pm 0.28$ & $38.63 \pm 0.31$ & $6.27 \pm 0.18$ \\
TN (\%, d.w.) & $3.02 \pm 0.06$ & $0.55 \pm 0.04$ & $2.73 \pm 0.05$ \\
C/N ratio (TOC/TN) & 13.36 & 70.24 & 2.30 \\
TP (\%, d.w.) & $1.03 \pm 0.02$ & $0.09 \pm 0.01$ & $0.41 \pm 0.04$ \\
pH & $7.29 \pm 0.41$ & N.D. & $7.03 \pm 0.09$ \\
\hline
\end{tabular}

The data are expressed as mean \pm standard deviation for triplicate determinations. N.D., no determination.

Experimental reactor. Schematic diagram of the experimental reactor is shown in Fig. 1.The anaerobic digesters were 1-L glass bottles with working volume of $500 \mathrm{~mL}$. Each bottle consisted of a gas sampling port and a feed inlet. It was sealed using a rubber stopper in which a pipe was used to exit biogas. The digester was connected to a gas collection system consisting of saturated brine $\left(\mathrm{NaHCO}_{3}\right)$ displacement bottle and a brine $\left(\mathrm{NaHCO}_{3}\right)$ gathering bottle. Prior to operation, the reactors were purged with nitrogen gas for $5 \mathrm{~min}$ to ensure anaerobic conditions. Thereafter, the digesters were placed in a water bath controlled at $35 \pm 1^{\circ} \mathrm{C}$.

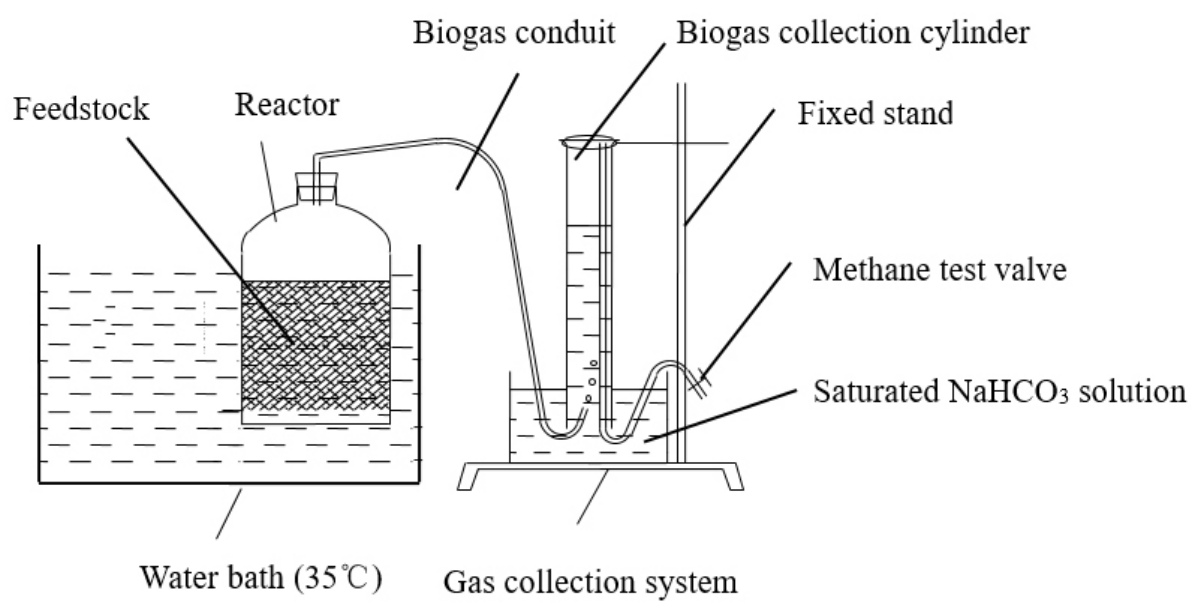

Fig. 1 Experimental reactor for semi-dry anaerobic co-digestion of swine manure and rice straw

Feedstock preparation. Three treatments and one control for semi-dry anaerobic co-digestion of swine manure and rice straw with biogas slurry inoculum at the total solid of around $15 \%$ were prepared: (a) CK (control reactor), $160 \mathrm{~g}$ swine manure, $40 \mathrm{~g}$ rice straw, $270 \mathrm{~mL}$ distilled water; (b) BS-1, $160 \mathrm{~g}$ swine manure, $40 \mathrm{~g}$ rice straw, $34 \mathrm{~mL}$ biogas slurry, $236 \mathrm{~mL}$ distilled water; (c) BS-2, $160 \mathrm{~g}$ swine manure, $40 \mathrm{~g}$ rice straw, $69 \mathrm{~mL}$ biogas slurry, $201 \mathrm{~mL}$ distilled water; (d) BS-1, $160 \mathrm{~g}$ swine manure, $40 \mathrm{~g}$ rice straw, $137 \mathrm{~mL}$ biogas slurry, $133 \mathrm{~mL}$ distilled water. The experimental design was shown in Table 2. 
Table 2 Experimental design for semi-dry anaerobic co-digestion of swine manure and rice straw with biogas slurry inoculation

\begin{tabular}{cccccccc}
\hline Treatment & $\begin{array}{c}\text { Inoculum ratio } \\
(\%)\end{array}$ & $\begin{array}{c}\text { SM } \\
(\mathrm{g})\end{array}$ & $\begin{array}{c}\text { RS } \\
(\mathrm{g})\end{array}$ & $\begin{array}{c}\mathrm{BS} \\
(\mathrm{mL})\end{array}$ & $\begin{array}{c}\mathrm{DW} \\
(\mathrm{mL})\end{array}$ & $\begin{array}{c}\text { Total } \\
\text { weight }(\mathrm{g})\end{array}$ & $\begin{array}{c}\text { Actual TS } \\
(\%)\end{array}$ \\
\hline CK & 0 & 140 & 60 & 0 & 270 & 470 & $15.70 \%$ \\
BS-1 & 1.2 & 140 & 60 & 34 & 236 & 470 & $15.01 \%$ \\
BS -2 & 2.4 & 140 & 60 & 69 & 201 & 470 & $15.23 \%$ \\
BS-3 & 4.8 & 140 & 60 & 137 & 133 & 470 & $15.40 \%$ \\
\hline
\end{tabular}

$T S$, total solid; SM, swine manure; RS, rice straw; BS, biogas slurry; DW, Distilled water. CK, control reactor without inoculum or pretreatment; BS-1, BS-2 and BS-3, reactors inoculated with biogas slurry at the proportions of $1.2 \%, 2.4 \%$ and $4.8 \%$ based on the TS of biogas slurry and substrate.

Analytical methods. Biogas production was measured by water displacement and methane concentration was measured by portable $\mathrm{CH}_{4}$ detector (Shenzhen Keernuo Electronics Technology Co., Ltd., China). TS and VS were determined using standard methods [24]. pH was detected by a $\mathrm{pH}$ meter (SenION1 portable $\mathrm{pH}$ meter, HACH, USA) in a 1:5 (w/v) water-soluble extract. Besides, the yields and productivities of biogas and methane after about 60 days were calculated following Equation (1) and (2).

$$
\begin{aligned}
& C_{\text {yield }}=\frac{P_{\text {total }}}{S_{\text {loaded }}} \times 10^{-3} \\
& C_{\text {productivity }}=\frac{P_{\text {total }}}{S_{\text {reduced }}} \times 10^{-3}
\end{aligned}
$$

where, $C_{\text {yield }}$ is the biogas/methane yields $\left(\mathrm{L} \mathrm{kg}^{-1} \mathrm{TS}\right.$ or VS-loaded); $C_{\text {prod }}$ is the biogas/methane productivity ( $\mathrm{L} \mathrm{kg}^{-1} \mathrm{TS}$ or VS-reduced); $P_{\text {total }}$ is the total production amounts of biogas/methane $(\mathrm{mL})$; $S_{\text {loaded }}$ is the loaded amounts of TS or VS in the reactor $(\mathrm{g}) ; S_{\text {reduced }}$ is the reduced amounts of TS or VS in the reactor $(\mathrm{g})$.

Statistical analysis. One-way ANOVA was performed to evaluate the data for any significant difference in terms of biogas and methane production and methane content. Biogas yield was calculated as the volume of biogas or methane production per unit weight of straw TS or VS loaded, and biogas productivity was referred to the volume of biogas or methane production per unit weight of straw TS or VS reduced. First-order kinetic models, the simplest models applied to one- or two-phase anaerobic digestion of complex substrates, have been successfully used to quantify the extent of process inhibition, assess the substrate availability, and discover the rate-limiting steps such as hydrolysis $[21,25,26]$. In this study, a first-order model was also used to compare the digestion performance of different reactors. The biogas or methane production rate constant $(k)$ was obtained from the following Equation (3) using the data analysis and graphing software (Origin 8.5).

$$
G=G_{T}\left(1-e^{-k t}\right)
$$

where, $G(\mathrm{~mL})$ is the cumulative biogas or methane production, $G_{T}(\mathrm{~mL})$ is the total biogas production in the anaerobic co-digestion, $k\left(\mathrm{~d}^{-1}\right)$ is the first-order biogas production rate constant, and $t$ (d) is the operation time, respectively.

\section{Results and discussion}

Daily biogas production. Fig. 2 shows the daily biogas production in the reactors of anaerobic co-digestion under different amounts of biogas slurry inoculation. The daily biogas production in all the reactors gradually increased from day 4 on, and reached the first peak on day 10, which was followed by a gradual decreasing tendency. Thereafter, the daily biogas production in the reactors with biogas slurry addition reached the second peaks on day 20 , while the CK was on day 32 . After 40 days' operation, the daily biogas production in all the reactors decreased from above $200 \mathrm{~mL} \mathrm{~d}^{-1}$ to below $100 \mathrm{~mL} \mathrm{~d}^{-1}$. The daily biogas production in the BS-3 reactor exhibited the best performance from day 15 to day 30, and reached greater than $700 \mathrm{~mL} \mathrm{~d}^{-1}$ during day $19-24$, while the daily biogas production in the BS-1 and BS-2 reactors also showed better performance than $\mathrm{CK}$, and reached 
nearly $700 \mathrm{~mL} \mathrm{~d}^{-1}$ on day 20 . The results indicate that biogas slurry inoculum is effective for the improvement of biogas production. After biogas slurry addition, the biogas production process was accelerated with earlier appearance of biogas production peaks.

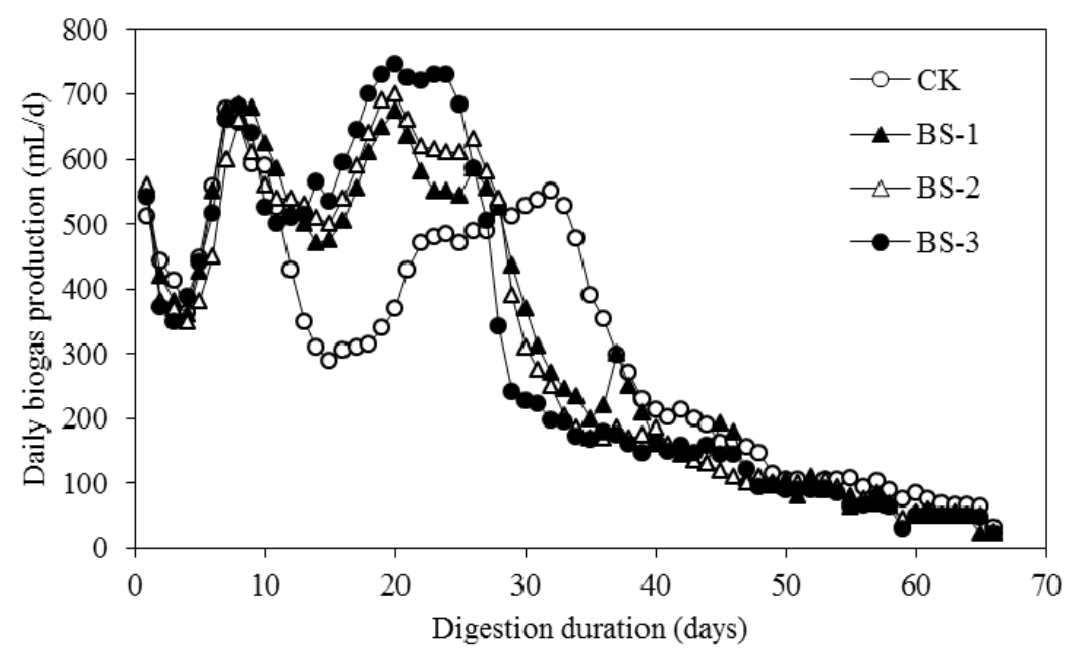

Fig. 2 Daily biogas production in the reactors during anaerobic co-digestion of swine manure with rice straw under different amounts of inoculum addition (CK: control without inoculum; BS-1, BS-2 and BS-3: reactors inoculated with biogas slurry at the proportions of $1.2 \%, 2.4 \%$ and $4.8 \%$ based on total solids of biogas slurry and substrate)

Methane content. Fig. 3 shows the daily methane content in the reactors of anaerobic co-digestion under different amounts of biogas slurry inoculation. The methane contents in all the reactors gradually increased in the first 10 days, and reached more than $70 \%$. Thereafter, the methane contents kept around $80 \%$ until the end of experiment. There was no significant difference among CK, BS-1, BS-2 and BS-3 $(p<0.05)$, meaning that biogas slurry inoculation had no obvious influence on methane content during the anaerobic co-digestion of swine manure with rice straw.

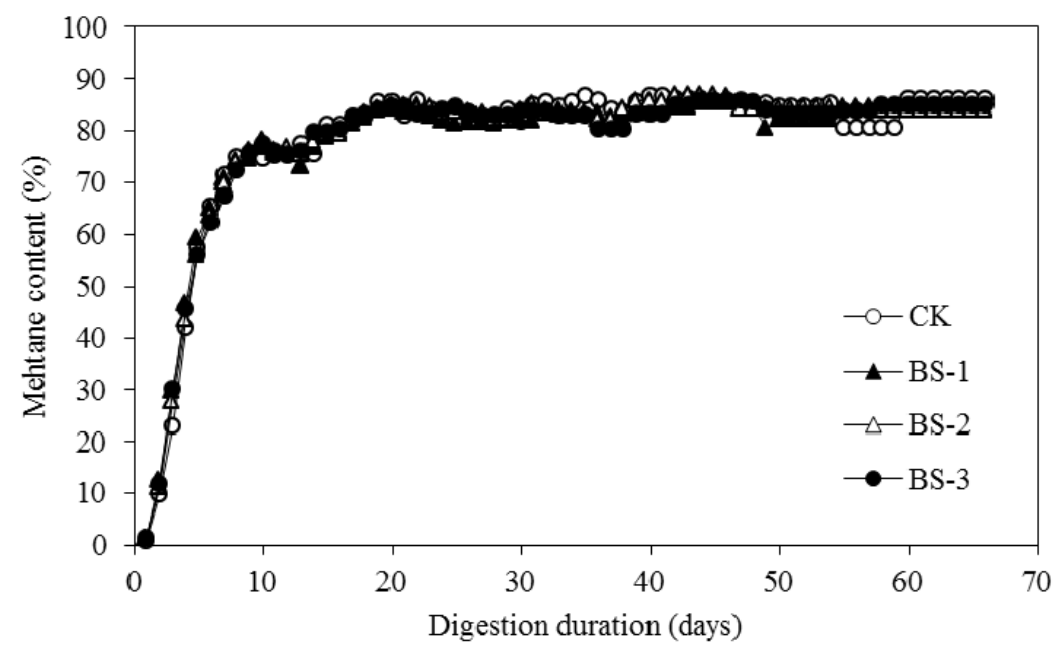

Fig. 3 Changes in methane content in the reactors during anaerobic co-digestion of swine manure with rice straw under different amounts of inoculum addition (CK: control without inoculum; BS-1, BS-2 and BS-3: reactors inoculated with biogas slurry at the proportions of $1.2 \%, 2.4 \%$ and $4.8 \%$ based on total solids of biogas slurry and substrate)

Cumulative biogas production. Fig. 4 shows the cumulative biogas production in the reactors of anaerobic co-digestion under different amounts of biogas slurry inoculation. During day 20 to day 40, the cumulative biogas production was higher in the reactors with biogas slurry addition in comparison to the control, and the overall biogas production in all the reactors could reach more than $20 \mathrm{~L}$. 


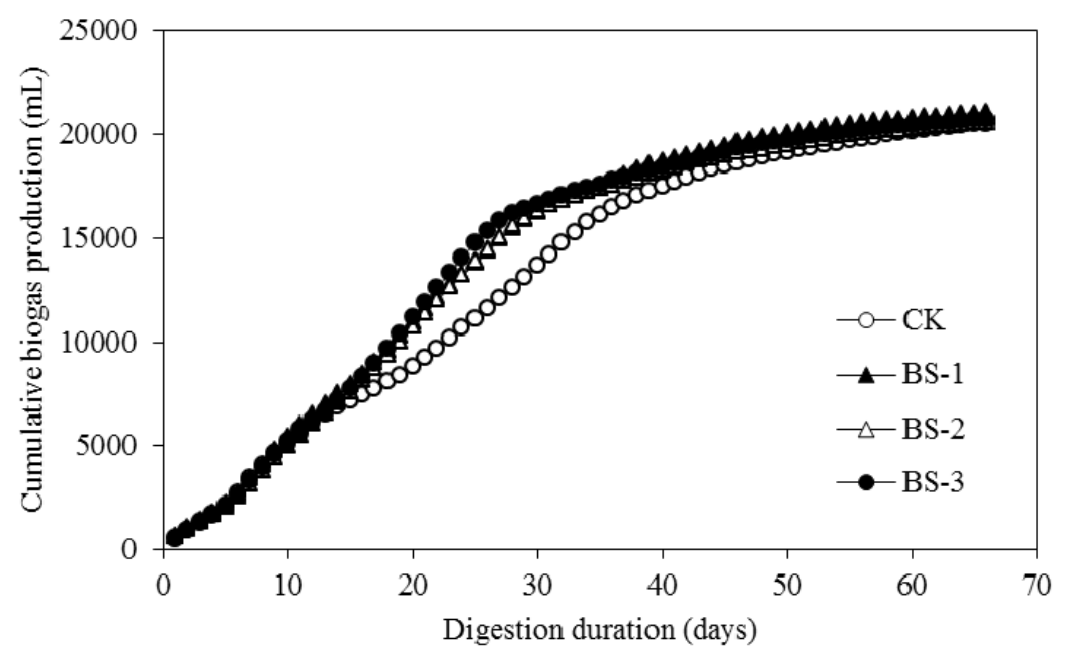

Fig. 4 Cumulative biogas production in the reactors during anaerobic co-digestion of swine manure with rice straw under different amounts of inoculum addition (CK: control without inoculum; BS-1, BS-2 and BS-3: reactors inoculated with biogas slurry at the proportions of $1.2 \%, 2.4 \%$ and $4.8 \%$ based on total solids of biogas slurry and substrate)

Average performance. Table 3 summarized the average performance of anaerobic co-digestion under different amounts of biogas slurry inoculation. The initial $\mathrm{pHs}$ in the reactors were ranged 7.44-7.68, while the final pHs were 7.97-7.99. After about 60-day's anaerobic digestion, $37.03-38.88 \%$ of TS and $42.03-45.05 \%$ of VS reduction could be achieved in the reactors. The average biogas yields varied between (278.02-297.62) L/kg-TS loaded or (339.29-367.56) L/kg-VS loaded, while the average biogas productivity were (714.99-773.39) L/kg-TS reduced or (753.09-871.22) L/kg-VS reduced. The average methane yields varied between (209.70-222.96) $\mathrm{L} / \mathrm{kg}$-TS loaded or (255.91-275.73) L/kg-VS loaded, while the average biogas productivity were (539.29-584.87) L/kg-TS reduced or (568.03-656.02) L/kg-VS reduced.

Compared to the $\mathrm{CK}$, the biogas and methane yields were increased by $3.00-7.05 \%$ and $2.83-6.32 \%$ in the reactors after biogas slurry inoculation, with their biogas and methane productivity being improved by 7.48-8.17\% and 6.75-8.45\%, respectively for per unit of TS. As for per unit of VS, the biogas and methane yields were increased by $5.60-8.33 \%$ and $5.95-7.74 \%$, with biogas and methane productivity being improved by $8.67-15.69 \%$ and $7.93-15.49 \%$, respectively. Among the reactors with different amounts of biogas slurry inoculum, no significant difference was found on the biogas and methane yields and productivity $(p<0.05)$, which indicated that a large amount of inoculum may have no remarkable effect on the overall biogas or methane yield and productivity, although biogas slurry inoculation could accelerate the progress of the whole anaerobic co-digestion.

According to the previous studies on theoretical methane yield of swine manure, the theoretical methane yield could reach more than $0.5 \mathrm{~m}^{3} \mathrm{~kg}^{-1} \mathrm{VS}$ [27], and the biogas production could be increased by about $10 \%$ when crop straw was added $[27,28]$. Besides, the selection of inoculum ratio was crucial as well as the anaerobic biodegradability of solid wastes. The selected inoculum source is reported to be responsible for achieving a rapid startup of balanced microbial population [21]. In case of anaerobic biodegradability of solid wastes, use of highly active anaerobic inoculum would reduce significantly the experimental time [29]. In this experiment, higher biogas yields and methane contents were obtained than other studies by using different raw materials including animal manures like swine manure, cattle manure and chicken manure, and crop straws like rice straw, wheat straw and switch grass $[21,26,30]$. The obtained methane yields $\left(568.03-656.02 \mathrm{~m}^{3} / \mathrm{kg}\right.$-VS reduced) were close or equal to the theoretical value. Biogas slurry inoculation did accelerate the biogas production process and shorten the digestion duration, which is in consistent with the results of Motte et al. (2013) and $\mathrm{Gu}$ et al. (2014). 
Table 3 Average performance of semi-dry anaerobic co-digestion of swine manure and rice straw with biogas slurry inoculation

\begin{tabular}{|c|c|c|c|c|}
\hline Parameters & $\mathrm{CK}$ & BS-1 & BS-2 & BS-3 \\
\hline \multicolumn{5}{|l|}{ pH values } \\
\hline Initial pH & 7.62 & 7.68 & 7.44 & 7.47 \\
\hline Final pH & 7.97 & 7.99 & 7.98 & 7.97 \\
\hline \multicolumn{5}{|l|}{ TS and VS values } \\
\hline Initial TS (g) & 73.79 & 70.5 & 71.581 & 72.38 \\
\hline VS (g) & 60.46 & 57.09 & 57.29 & 56.60 \\
\hline VS/TS & 0.82 & 0.81 & 0.80 & 0.78 \\
\hline Final TS $(g)$ & 45.10 & 43.20 & 45.02 & 45.58 \\
\hline VS (g) & 33.22 & 31.45 & 32.78 & 32.81 \\
\hline VS/TS & 0.74 & 0.73 & 0.73 & 0.72 \\
\hline TS reduction (\%) & 38.88 & 38.73 & 37.10 & 37.03 \\
\hline VS reduction (\%) & 45.05 & 44.91 & 42.77 & 42.03 \\
\hline \multicolumn{5}{|l|}{ Biogas production } \\
\hline Yield (L/kg-TS loaded) & 278.02 & 297.62 & 286.74 & 286.37 \\
\hline Yield (L/kg -VS loaded) & 339.29 & 367.56 & 358.30 & 366.19 \\
\hline $\begin{array}{l}\text { Productivity (L/kg-TS } \\
\text { reduced) }\end{array}$ & 714.99 & 768.50 & 772.85 & 773.39 \\
\hline $\begin{array}{l}\text { Productivity (L/kg-VS } \\
\text { reduced) }\end{array}$ & 753.09 & 818.38 & 837.63 & 871.22 \\
\hline \multicolumn{5}{|l|}{ Methane production } \\
\hline Yield (L/kg-TS loaded) & 209.70 & 222.96 & 217.00 & 215.63 \\
\hline Yield (L/kg-VS loaded) & 255.91 & 275.35 & 271.15 & 275.73 \\
\hline $\begin{array}{l}\text { Productivity (L/kg-TS } \\
\text { reduced) }\end{array}$ & 539.29 & 575.70 & 584.87 & 582.35 \\
\hline $\begin{array}{l}\text { Productivity (L/kg-VS } \\
\text { reduced) }\end{array}$ & 568.03 & 613.07 & 633.90 & 656.02 \\
\hline
\end{tabular}

$C K$, control without inoculum; BS-1, BS-2 and BS-3, reactors inoculated with biogas slurry at the proportions of $1.2 \%$, $2.4 \%$ and $4.8 \%$ based on the TS of biogas slurry and substrate.

Modelling and kinetics. For the purpose of understanding the biogasification process during anaerobic digestion, kinetic parameters are usually utilized to analyze the performance of biogas or methane production in the reactors. In this study, single-stage first order kinetic model was used to evaluate the anaerobic co-digestion of swine manure with rice straw under different amounts of biogas slurry inoculum and different pretreatment methods for rice straw.

Table 4 and Fig. 5 show the characteristics of single-stage first order kinetic model for anaerobic co-digestion of swine manure with rice straw under different amounts of biogas slurry inoculum and different pretreatment methods for rice straw. In the reactors with different amounts of biogas slurry addition, the biogas production rate constants $\left(k=0.0208-0.0314 \mathrm{~d}^{-1}\right)$ obtained from the 66 days' operation indicated that, BS-1, BS-2 and BS-3 exhibited faster in biogasification with their $k$ increased by $39.90 \%, 40.38 \%$ and $50.96 \%$ respectively compared to CK.

For the single-stage first order kinetics of anaerobic digestion, Liang et al. (2011) and Liang et al. (2014) reported that the biogas production rate constants for dry anaerobic digestion of smooth cordgrass ranged from 0.022-0.052 after being pretreated by lime, hot-water or thermo-lime, which agrees with the single-stage first-order biogas production rate constants obtained in this study. Kafle and Kim (2013) obtained the biogas production rate constants ranging from 0.032-0.077 for anaerobic co-digestion of swine manure with apple waste, greater than the results in this study, most probably due to their lower TS $(<5 \%)$ and more inoculum applied $\left(\mathrm{VS}_{\text {substrate }} / \mathrm{VS}_{\text {inoculum }}=0.5-1.0\right)$.

For the single-stage first order kinetics of anaerobic digestion, Lei et al. (2010) achieved the biogas production rate constants in the first and second stages about 0.012-0.015 and 0.045-0.046, respectively for anaerobic digestion of rice straw and anaerobic sludge. Their constants were lower in the first stage and higher in the second stage than the results from this study, which implies that faster biogasification could be realized by using pretreated rice straw. 
Table 4 Characteristics of first-order kinetic for semi-dry anaerobic co-digestion of swine manure and rice straw with biogas slurry inoculation

\begin{tabular}{clll}
\hline Treatment & $G_{T}(\mathrm{~mL})$ & $k\left(\mathrm{~d}^{-1}\right)$ & $R^{2}$ \\
\hline CK & $29174 \pm 1035$ & $0.0208 \pm 0.0012$ & 0.9868 \\
BS-1 & $25892 \pm 679$ & $0.0291 \pm 0.0015$ & 0.9826 \\
BS-2 & $24769 \pm 748$ & $0.0292 \pm 0.0017$ & 0.9770 \\
BS-3 & $24891 \pm 720$ & $0.0314 \pm 0.0019$ & 0.9743 \\
\hline
\end{tabular}

$C K$, control without inoculum or pretreatment; BS-1, BS-2 and BS-3, reactors inoculated with biogas slurry at the proportions of $1.2 \%, 2.4 \%$ and $4.8 \%$ based on the total solids of biogas slurry and raw materials; $G_{T}$, theoretical total biogas yield; $k$, biogas production rate constant; $R^{2}$, coefficient of determination. The data are expressed as mean \pm standard deviation for triplicate determinations.
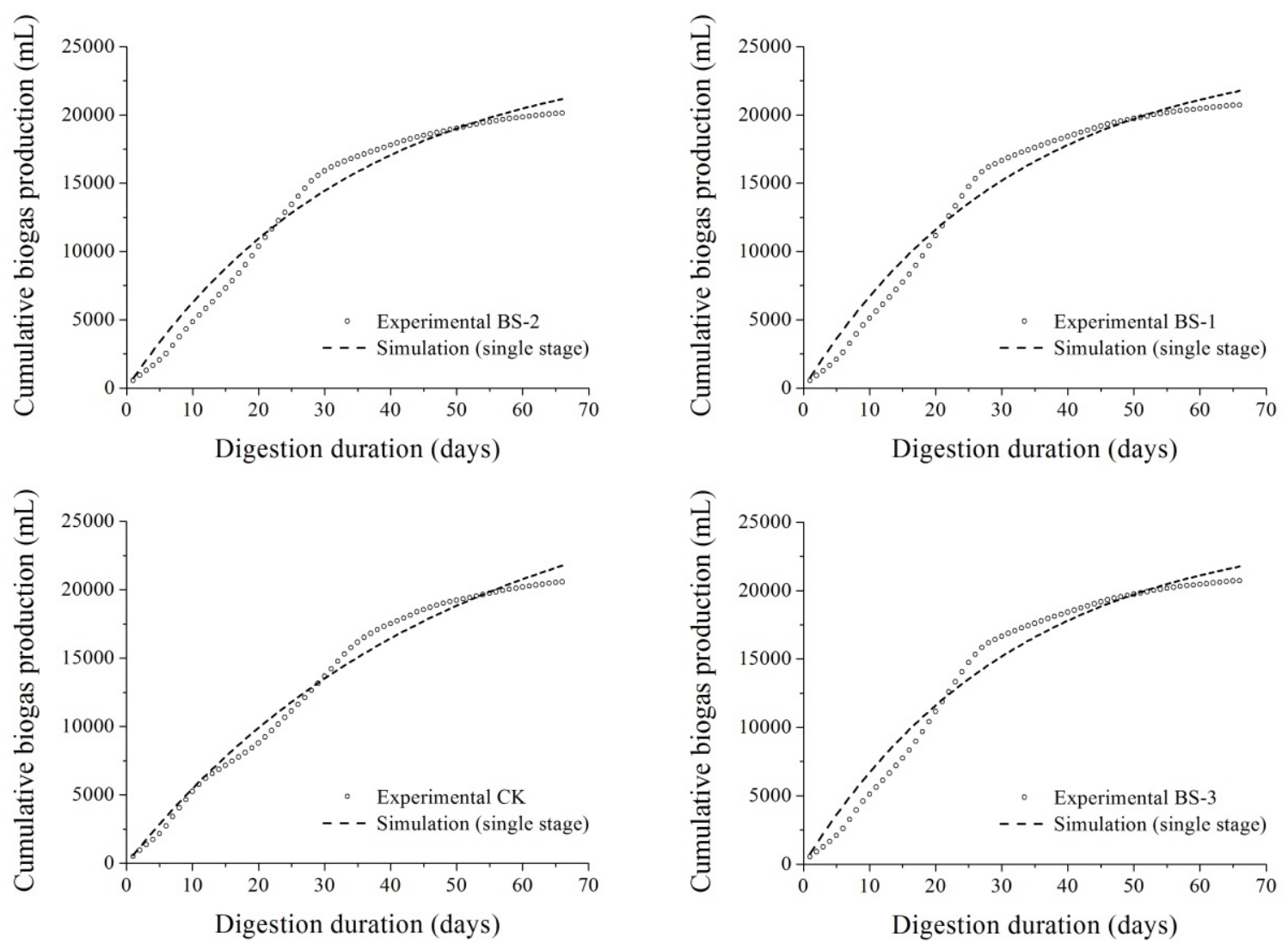

Fig. 5 Comparison between experimental data and simulated results from the single-stage first-order models for anaerobic co-digestion of swine manure with rice straw under different amounts of inoculum addition (CK: control without inoculum; BS-1, BS-2 and BS-3: reactors inoculated with biogas slurry at the proportions of $1.2 \%, 2.4 \%$ and $4.8 \%$ based on total solids of biogas slurry and raw materials)

\section{Conclusions}

Biogas slurry inoculation increased biogas yield by $3.00-7.05 \%$, and improved biogas productivity by $7.48-8.17 \%$, for per unit of TS. The digestion process fitted the single-stage first-order model well, and the reactors inoculated with biogas slurry exhibited faster in biogas production with the biogas production rate constant $(k)$ increased by $39.90-50.96 \%$ compared to the control reactor.

\section{Acknowledgements}

The work was supported by the Key Program of Agricultural Non-point Source Pollution Control in Upper Huangpu River Water Source Conservation Zone funded by Shanghai Environmental Protection Bureau (2011-51), and the authors would like to thank Mr. Zigang Zhao, Mr. Shaofeng Yu 
and Ms. Chengkai Zhu from Qingpu Modern Agriculture Park for their help in collecting and preparing of the raw materials.

\section{References}

[1] G. Shen, X. Qian, Z. Yao, Z. Xu, S. Huang, Z. Yan, Evaluation of livestock and poultry breeding carrying capacity of arable lands in Shanghai suburbs, Livestock Environment VII - Proceedings of the Seventh International Symposium, Beijing, May 2005, 452-457.

[2] Y. Gu, X. Chen, Z. Liu, X. Zhou, Y. Zhang, Effect of inoculum sources on the anaerobic digestion of rice straw, Bioresour. Technol. 158 (2014) 149-155.

[3] X. Qian, G. Shen, Z. Wang, C. Guo, Y. Liu, Z. Lei, Z. Zhang, Co-composting of livestock manure with rice straw Characterization and establishment of maturity evaluation system. Waste Manage. 34 (2014) 530-535.

[4] D. Li, Z. Yuan, Y. Sun, Semi-dry mesophilic anaerobic digestion of water sorted organic fraction of municipal solid waste (WS-OFMSW), Bioresour. Technol. 101 (2010) 2722-2728.

[5] Z. Lei, J. Chen, Z. Zhang, N. Sugiura, Methane production from rice straw with acclimated anaerobic sludge: Effect of phosphate supplementation, Bioresour. Technol. 101 (2010) 4343-4348.

[6] F. Raposo, M.A. De la Rubia, V. Fernández-Cegrí, R. Borja, Anaerobic digestion of solid organic substrates in batch mode: An overview relating to methane yields and experimental procedures, Renew.Sust. Energ. Rev. 16 (2011) 861-877.

[7] W. Zhong, Z. Zhang, Y. Luo, S. Sun, W. Qiao, M. Xiao, Effect of biological pretreatments in enhancing corn straw biogas production, Bioresour. Technol. 102 (2011) 11177-11182.

[8] M. Niu, X. Pang, S. Chen, The study of influencing factors to corn straw mixed with pig effluent anaerobic fermentation, Proc. Environ. Sci. 8 (2011) 54-60.

[9] A. Abbassi-Guendouz, D. Brockmann, E. Trably, C. Dumas, J.P. Delgenès, J.P. Steyer, R. Escudié, Total solids content drives high solid anaerobic digestion via mass transfer limitation, Bioresour. Technol. 111 (2012) 55-61.

[10]L. De Baere, B. Mattheeuws, State of the art of anaerobic digestion in Europe, in: International Water Association, 12th World Congress on Anaerobic Digestion, 31 Oct - 4 Nov., Guadalajara, Mexico, 2010, pp. 1-7.

[11] S.E. Nayono, C. Gallert, J. Winter, Foodwaste as a co-substrate in a fed-batch anaerobic biowaste digester for constant biogas supply, Water Sci. Tech. 59 (2009) 1169-1178.

[12]D. Bolzonella, L. Innocenti, P. Pavan, P. Traverso, F. Cecchi, Semi-dry thermophilic anaerobic digestion of the organic fraction of municipal solid waste: focusing on the start-up phase, Bioresour. Technol. 86 (2003) 123-129.

[13]H.K. Ahn, M.C. Smith, S.L. Kondrad, J.W. White, Evaluation of biogas production potential by dry anaerobic digestion of switchgrass-animal manure mixtures, Appl. Biochem. Biotechnol. 160 (2010) 965-975.

[14]M. Krishania, V.K. Vijay, R. Chandra, Methane fermentation and kinetics of wheat straw pretreated substrates co-digested with cattle manure in batch assay, Energy, 57 (2013) 359-367.

[15]J.C. Motte, R. Escudié, N. Bernet, J.P. Delgenes, J.P. Steyer, C. Dumas, Dynamic effect of total solid content, low substrate/inoculum ratio and particle size on solid-state anaerobic digestion, Bioresour. Technol. 144 (2013) 141-148. 
[16]A. Bayane, S.R. Guiot, Animal digestive strategies versus anaerobic digestion bioprocesses for biogas production from lignocellulosic biomass, Rev. Environ. Sci. Bio-Technol. 10 (2011) 43-62.

[17]E. Elbeshbishy, G. Nakhla, H. Hafez, Biochemical methane potential (BMP) of food waste and primary sludge: influence of inoculum pre-incubation and inoculum source, Bioresour. Technol. 110 (2012) 18-25.

[18]L. Li, X. Yang, X. Li, M. Zheng, J. Chen, Z. Zhang, The influence of inoculum sources on anaerobic biogasification of $\mathrm{NaOH}$-treated corn stover, Energy Sources Part A 33 (2011) 138-144.

[19] S. Suwannoppadol, G. Ho, R. Cord-Ruwisch, Rapid start-up of thermophilic anaerobic digestion with the turf fraction of MSW as inoculum, Bioresour. Technol. 102 (2011) 7762-7767.

[20]Y. Zhou, Z. Zhang, T. Nakamoto, Y. Li, Y. Yang, M. Utsumi, N. Sugiura, Influence of substrate-to-inoculum ratio on the batch anaerobic digestion of bean curd refuse-okara under mesophilic conditions, Biomass Bioenerg. 35 (2011) 3251-3256.

[21] W.S. Lopes, V.D. Leite, S. Prasad, Influence of inoculum on performance of anaerobic reactors for treating municipal solid waste, Bioresour. Technol. 94 (2004) 261-266.

[22] L. Neves, R. Oliveira, M.M. Alves, Influence of inoculum activity on the biomethanization of a kitchen waste under different waste/inoculum ratios, Process Biochem. 39 (2004) 2019-2024.

[23]L. Maya-Altamira, A. Baun, I. Angelidaki, J.E. Schmidt, Influence of wastewater characteristics on methane potential in food-processing industry wastewaters, Water Res. 42 (2008) 2195-203.

[24]APHA (American Public Health Association), Standard methods for the examination of water and wastewater, Washington DC, American Public Health Association, 1998.

[25]G.K. Kafle, S.H. Kim, Anaerobic treatment of apple waste with swine manure for biogas production: Batch and continuous operation, Appl. Energ. 103 (2013) 61-72.

[26] Y. Liang, Z. Zheng, R. Huang, X. Luo, A preliminary study of simultaneous lime treatment and dry digestion of smooth cordgrass for biogas production, Chem. Eng. J. 174 (2011) 175-181.

[27]H.B. Møller, S.G. Sommer, B. Ahring, Methane productivity of manure, straw and solid fractions of manure, Biomass Bioenerg. 26 (2004) 485-495.

[28] G. Wang, H.N. Gavala, I.V. Skiadas, B.K. Ahring, Wet explosion of wheat straw and codigestion with swine manure: effect on the methane productivity, Waste Manage. 29 (2009) 2830-2835.

[29]T. Forster-Carneiro, M. Pérez, L.I. Romero, D. Sales, Dry-thermophilic anaerobic digestion of organic fraction of the municipal solid waste: focusing on the inoculum sources, Bioresour. Technol. 98 (2007) 3195-3203.

[30]J. Ye, D. Li, Y. Sun, G. Wang, Z. Yuan, F. Zhen, Y. Wang, Improved biogas production from rice straw by co-digestion with kitchen waste and pig manure, Waste Manage. 33 (2013) 2653-2658. 